\title{
IMIGRAÇÃO, CIÊNCIA E SAÚDE: CONTROLE DE RISCOS E EXPANSÃO DE DIREITOS NA BACIA DO RIO DA PRATA (1873-1911)
}

\author{
Fernanda Rebelo-Pinto \\ Doutora em História das Ciências e da Saúde, Instituto de Humanidades, Artes e Ciências Milton Santos e Programa de Pós-Graduação \\ em Ensino, Filosofia e História das Ciências da Universidade Federal da Bahia - IHAC/PPGEFHC-UFBA \\ fernanda.rebelo@ufba.br
}

Recibido: 1 octubre 2015 ;Aceptado: 30 mayo 2016.

Cómo citar este artículo/Citation: Rebelo-Pinto, Fernanda (2016), "Imigração, ciência e saúde: controle de riscos e expansão de direitos na Bacia do Rio da Prata (1873-1911)", Asclepio, 68 (2): p155. doi: http://dx.doi.org/10.3989/asclepio.2016.27

RESUMO: Este artigo analisa como o processo imigratório nos países da Bacia do Rio da Prata, em especial Brasil e Argentina, promoveu inflexões na assinatura de acordos sanitários no final do século XIX. O porto é compreendido como um dispositivo onde se definem saberes e normas e se estabelecem intervenções sobre as populações em trânsito, em especial imigrantes. Os entraves na assinatura de convenções sanitárias entre estes países estavam não só relacionados às controvérsias no interior das comunidades médico-científicas como também às tensões políticas e econômicas vinculadas à disputa por mão de obra imigrante. Nas primeiras décadas do século $\mathrm{XX}$, assistimos a um deslocamento de interesses e problemas relacionados à saúde pública. Não bastava mais só conter epidemias, os estados nacionais deveriam garantir certos benefícios às populações, em especial associados à assistência à saúde. Esta nova perspectiva é analisada a partir das compreensões e usos da ideologia liberal no que diz respeito à auto-regulação dos riscos, à coletivização de bemestar e à expansão de direitos civis e sociais, alavancados, em parte, pela inclusão da população imigrante nestas sociedades.

PALAVRAS-CHAVE: Imigração; Diplomacia; Epidemias; América do sul; Biopolítica.

\section{IMMIGRATION, SCIENCE AND HEALTH: RISKS CONTROL AND EXPANDING RIGHTS IN THE RIO DE LA PLATA BASIN (1873-1911)}

ABSTRACT: This paper analyzes how immigration process in the Rio de Plata Basin countries, specifically Brazil and Argentina, promoted inflexions in the sanitations agreements in the end of 19th century. The port is a device within in which are defined knowledge and standards and are established interventions on people in transit, particularly immigrants. The barriers in the agreements between these countries were not only related to controversies within medical and scientific communities but also to political and economics tensions linked to the labor immigrants disputes. In the beginning of 20th century, we can see a shift of interest and issues related to public health: epidemic control was not enough. The states must guarantee some benefits to the populations, especially heath care. This new view is analyzed according to the understanding and uses of the liberal ideology concerning risk self-regulations, collectivization of welfare and expanding of civil and social rights. This process is leveraged in parts by the inclusion of the immigrants in theses societies.

KEY WORDS: Immigration; Diplomacy; Outbreaks; South America; Biopolitcs.

Copyright: (C) 2016 CSIC. Este es un artículo de acceso abierto distribuido bajo los términos de la licencia Creative Commons Attribution (CC BY) España 3.0. 


\section{INTRODUÇÃO}

A partir da última metade do século XIX, diferentes países, tanto no continente europeu, quanto no americano, passaram a contemplar alguma forma de cooperação sanitária. Pretende-se analisar este processo a partir da compreensão do porto enquanto um dispositivo onde se definem saberes e normas e se estabelecem intervenções sobre as populaçõe ${ }^{1} \mathrm{em}$ trânsito, em especial imigrantes. Estas intervenções são baseadas nos pressupostos da ciência médica do século XIX que informavam as práticas de profilaxia sanitária ${ }^{2}$.

O problema das epidemias motivou a assinatura de convênios de cooperação sanitária entre países com o intuito de proteger suas fronteiras para que doenças não se alastrassem pelos territórios. Estes acordos começaram a ser discutidos em conferências, nas quais se reuniam representações médicas e diplomáticas para discutir como prevenir a entrada de enfermidades pelos portos, sem prejudicar o livre comércio. No entanto, algumas questões dificultavam a assinatura destes convênios e, consequentemente, a hegemonização das práticas sanitárias nos portos como: controvérsias científicas entre as comunidades médicas; interesse políticos e econômicos de cada nação.

Apesar das dificuldades dos países em chegarem a acordos para homogeneizar as práticas sanitárias nos portos, na primeira década do século $X X$, tais práticas encontram-se bem consolidadas graças às convenções. No entanto, neste mesmo período, identificamos um deslocamento de interesses no que diz respeito às políticas de saúde. Não bastava mais somente combater epidemias nas fronteiras e portos. 0 processo de construção dos estados nacionais ditava a necessidade também de promover um maior cuidado para com a população, em especial relacionado à assistência à saúde. Além disso, a opinião pública internacional, frente à emergência de um discurso humanitário, passa a dar uma maior atenção para as formas desumanas como ocorriam a travessia imigratória, a recepção e o tratamento de imigrantes pelos países receptores de mão de obra, especialmente na América do Sul.

Neste artigo, defendo que o processo imigratório e a assimilação de cidadãos europeus pelos países da Bacia do Prata deram origem à certas políticas direcionadas à coletivização de bem-estar e, consequentemente, à uma certa expansão de direitos sociais. Este processo é fruto de alguns elementos que serão discutidos como a relação entre países imigrantistas e emigrantistas no que diz respeito a recepção de uma população estrangeiras de forma tutelada ${ }^{3}$ - uma população livre, branca, assalariada e detentora de certos benefícios em seus países de origem; a construção de políticas sociais, em especial de saúde, direcionadas a certos grupos nos processos de construção das nações; e as peculiaridades no que diz respeito à recepção e aplicação das ideias liberais nos países da Bacia do Rio da Prata e sua relação com as diversas formas de se pensar políticas sociais de saúde.

Na primeira parte deste artigo, serão discutidas as diferenças entre os modelos de convenções europeias e platinas. Em seguida, analisaremos as diferenças entre as práticas de profilaxia aplicadas nos portos dos países da Bacia do Rio da Prata, em especial Brasil e Argentina, em um contexto de transição dos pressupostos científicos entre a teoria dos miasmas e a emergência da microbiologia, junto à compreensão do papel dos insetos na transmissão de doenças. Depois, trabalharemos as causas destas diferenças que transitam entre controvérsias no interior das comunidades médico-científicas e tensões políticas e econômicas geradas pela disputa por mão de obra imigrante entre Brasil, Argentina e Uruguai. Finalmente, mostraremos como a inclusão da população imigrante nestas sociedades fomentou, em parte, as discussões a respeito da expansão de direitos sociais, junto à recepção da ideologia liberal na região que prega, ao invés da competição, a conciliação de interesses entre as nações e a auto-regulação, inclusive dos riscos sociais.

A experiência com as epidemias teve papel determinante na percepção das elites políticas sobre problemas sociais, dando origem à certas ações políticas. As doenças passam a ser compreendidas como problema de natureza coletiva, interdependente ${ }^{4}$, em contexto local, e tema de debate da política internacional. A assistência à saúde é um capítulo importante na constituição dos estados de bem-estar-social. A partir de meados do século XIX, as conferências sanitárias internacionais foram fóruns de debates científicos e diplomáticos (Lima, 2002, p.36).

A primeira conferência sanitária no continente europeu ocorreu em Paris, no ano de 1850. Nas primeiras conferências e convenções sanitárias europeias, o moderno internacionalismo pode ser compreendido como produto do também moderno nacionalismo, junto à percepção do crescimento da dependência mútua entre países. $O$ internacionalismo médico da metade do século XIX percebe a doença como uma ameaça comum ao continente, uma ameaça que vem de fora, uma doença exótica. Por exemplo, uma doença asiática, no caso da cólera (Bynum, 1993, p. 423). 
O porto era compreendido como o local por onde as doenças adentravam os territórios e se alastravam pelo interior do país ${ }^{5}$. Portanto, o objetivo destas conferências estava em diminuir e tornar mais precisas as práticas de contenção de epidemias nos portos ${ }^{6}$ sem comprometer as trocas comerciais e a livre circulação de pessoas e bens ${ }^{7}$.

O movimento pela investigação em saúde pública tem origem no temor muito concreto das epidemias. Tal apreensão suscitou tentativas de implementação de politicas higiênicas e sanitárias comuns. Com o advento da teoria microbiana das doenças, esse movimento promoveu um esforço de homogeneização das práticas de laboratório utilizadas para reconhecer os agentes transmissíveis. Isto foi estruturado através das conferências sanitárias internacionais (Löwy, 2006, p. 32).

Entre 1851 e 1938, ocorreram as conferências europeias com o intuito de estudar em que medida poderia ser concebível suprimir as quarentenas sem colocar em risco a saúde da população, sendo a primeira convenção, o primeiro acordo sanitário entre nações europeias, assinada somente em 1896 em Veneza. A higiene torna-se, então, uma questão não mais somente científica, mas também diplomática (Löwy, 2006, p. 33).

Neste período, ocorreram quatorze conferências europeias, sendo que somente a $5^{\mathfrak{a}}$, em 1881 , foi realizada nos EUA, em Washington D.C. Todas as outras ocorreram em território europeu. A conferência realizada em Washington marca a entrada dos norte-americanos no âmbito da ação diplomática no campo da saúde e também a participação, pela primeira vez, de nações latino-americanas como Argentina, Bolívia, Brasil, México, Haiti, Venezuela, Chile e Peru. A febre amarela era a questão principal para os EUA. Em função dos surtos epidêmicos desta doença no país, os norte-americanos, entre 1857 e 1860, já haviam realizado quatro Convenções Nacionais de Quarentena e Saúde. A conferência de 1881 deu continuidade às suas políticas de saúde, interessadas no enfoque ao combate à febre amarela, doença considerada como originária do Caribe e da América do Sul (Chaves, 2009).

\section{CONVENÇÕES PLATINAS X CONVENÇÕES EUROPEIAS}

O movimento de cooperação sanitária internacional surgiu da necessidade de controlar surtos epidêmicos que atingiam grandes extensões de terra e ultrapassavam as fronteiras legais constituídas entre os países. No caso europeu, o objetivo era barrar dois inimigos comuns, a cólera asiática e a peste levantina. No entanto, desde o ano de 1873, as repúblicas platinas, Argentina e Uruguai, e o Império Brasileiro já haviam começado um processo de cooperação sanitária para resolver problemas causados pela epidemia de cólera na Bacia do Prata, mas também o problema da febre amarela, ambos atrelados à corrente imigratória (Chaves, 2009).

O internacionalismo nas conferências sanitárias europeias tinha seus limites, tanto pela exclusão de doenças consideradas como tropicais, como a febre amarela, que não era ameaça direta para o continente europeu, como na recusa a discutir as questões sanitárias ligadas à travessia de mão de obra imigrante da Europa para a América (Bynum,1993, p.432).

O ministro do interior argentino, Joaquim Gonzales, em 8 de abril de 1904, véspera da convenção do Rio de Janeiro, expôs o problema:

En Europa tambien se han celebrado varias conferencias sanitárias desgraciadamente sin que hayamos sido invitados a ellas. En estos congresos, se ha tenido en cuenta solo dos enfermedades, el cólera i la peste, esta última unicamente en la última conocida con el nombre de Conferencia de Venecia, em 1896. Como en general ha querido verse erroneamente en lo sancionado por estas reuniones, el código sanitário general del mundo entero, conviene que nos detenhamos um instante para hacer ressaltar aunque sea someramente las diferencias primordiales que existen entre la Europa i nosotros respecto de estos puntos [sic.] ${ }^{8}$.

Países latino-americanos, em especial aqueles com fronteiras na Bacia do Prata, tinham demandas diferentes daquelas da Europa e criaram um modelo de conferência distinto do europeu ${ }^{10}$. Entre Brasil, Argentina e Uruguai não havia o propósito coletivo de defesa que unia a Europa contra os inimigos comuns (a cólera e a peste). Pelo contrário, a febre amarela, enfermidade não tomada em conta na Europa, residia, para os argentinos, endemicamente no Brasil. A proximidade entre seus portos era mais curta que o período de incubação da doença, que segundo se acreditava, era de oito dias ${ }^{11}$.

Antes da assinatura das convenções platinas ${ }^{12}$, estas questões já vinham sendo discutidas não só pelas diplomacias dos países, mas também de forma mais ampla nas sociedades, como nos jornais de grande circulação. Em 16 de abril de 1873, por exemplo, um periódico uruguaio chamado El Siglo fez a seguinte pergunta às autoridades sanitárias argentinas quando estas pediram às autoridades sanitárias uruguaias que fechassem seus portos para navios procedentes do Brasil por causa da febre amarela: "Porque precavernos de las procedências del Brasil, si tenemos aqui la misma epidemia que allí tienen?" [sic] (Chaves, 2009, p. 73). 
Enquanto a Europa era invadida pela cólera ou pela peste, cada nação tomava as medidas que acreditava eficazes num período de transição de pressupostos científicos entre a higiene dos miasmas e a microbiologia $^{13}$. Esta tomada de decisão ocorria dentro das prescrições aceitas de comum acordo nas conferências, com as modificações impostas segundo interesses em jogo e as necessidades de cada Estado. Assim, existiam as convenções e os regulamentos sanitários distintos, o italiano, francês, inglês. Há algo mais importante e que caracterizava a natureza das conferências sanitárias europeias, diferenciando-as das convenções platinas. Aquelas eram conferências encarregadas de buscar a fórmula mais equitativa e adiantada para defender as nações contra a invasão de flagelos. Os estados eram livres para aceitarem ou não as conclusões e poderiam adotar todas ou algumas delas ${ }^{14}$

Muito diferente era o caráter e natureza das convenções platinas. Aprovadas as resoluções pela diplomacia dos países contratantes, elas eram submetidas à aprovação dos congressos nacionais respectivos para serem transformadas em tratados solenes, que tinham que ser aceitos sem modificação alguma das cláusulas.

De acordo com o ministro das relações exteriores argentino, José Terry, para unificar a profilaxia sanitária entre os quatro países contratantes desta convenção (Brasil, Argentina, Uruguai e Paraguai), era necessário fazer "abstrações das questões científicas que deveriam ser estudadas mais tarde".

De este hecho diferencial tan importante, se desprende la necesidad de tomar resoluciones que no respondan unicamente á los adelantos y dictados de la ciencia pura, hermosa en sus concepciones generales, pero dificiles de ser llevadas á la práctica dadas las condiciones y recursos del terreno en que van á ser aplicados $^{15}$ [sic.].

Ou seja, não era possível aplicar os pressupostos científicos rigorosamente na elaboração dos acordos dada as imensas diferenças de salubridades entre tais nações. Enquanto existisse endemicamente a febre amarela no Brasil e enquanto, no Paraguai, houvesse uma carência de instituições de defesa sanitária, eficazes para salvaguardar a saúde pública. A Argentina, considerada, pelas suas autoridades de saúde, a mais adiantada das nações do ponto de vista sanitário, tinha imensos interesses comerciais para defender, "intereses que se encuentran sujeitos a cada instante á las vaivenes de uma política sanitaria, que no se ha caracterizado durante estos últimos años por su estabilidad" [sic ${ }^{16}$.
Assim, pode-se abrir esta análise para a seguinte pergunta: por que países possuíam políticas de profilaxia diferentes, ainda que tivessem problemas epidemiológicos similares? ${ }^{17}$ Uma das fontes explicativas para a resposta pode estar na conexão entre o sistema político e cultural e o modo de compreensão das doenças contagiosas, ou seja, a aproximação entre política e ciência ${ }^{18} 19$.

\section{POLÍTICA, CIÊNCIA E SAÚDE}

Para Chaves (2006, 2009), o surgimento de convenções sanitárias entre Brasil, Argentina e Uruguai integra-se ao movimento sanitário já existente na Europa e EUA, compartilhando da concepção de que somente o poder público poderia solucionar os problemas de saúde da população e os problemas econômicos advindos das doenças epidêmicas. As convenções platinas de 1873 e 1887 são analisadas em uma perspectiva de integração a eventos similares na Europa e América do Norte, a partir da segunda metade do século XIX, como se fizessem parte de um movimento internacional de combate às epidemias. Uma historiografia mais clássica da saúde pública, como o trabalho pioneiro de Howard-Jones (1975), adota esses acontecimentos como fenômenos distintos.

Com intuito de dialogar um pouco com estas duas perspectivas de análise, é oportuno ressaltar que existiam demandas distintas e particularidades nas relações entre os três países -Argentina, Brasil e Uruguai- que é preciso levar em consideração. Estas particularidades tem conexão com o aceite ou rejeição, pelas comunidades científicas, dos novos pressupostos manipulados então pela teoria dos germes, junto à emergência da compreensão dos insetos vetores na transmissão de doenças infecciosas. Especialmente o papel do mosquito na transmissão da febre amarela ${ }^{20}$ e o da pulga do rato na transmissão da peste bubônica.

Um outro ponto que deve-se também levar em consideração diz respeito às disputas entre Brasil e Argentina pela mão de obra imigrante, importantíssima para a economia destes países. Finalmente, também precisamos atentar para a questão da hegemonia política no âmbito da Bacia do Prata, local de extrema importância econômica para o comércio de ambos países. Estes interesses, por sua vez, não podem ser compreendidos sem relacioná-los à influência de outras potências na região, em especial dos EUA e da Inglaterra ${ }^{21}$ (Fausto \& Devoto, 2004).

As relações entre Brasil e Argentina foram caracterizadas pela rivalidade, com momentos de aproxima- 
ção, em geral frustrados pela ação de grandes potências. Essas rivalidades tiveram início com a expansão territorial brasileira e a disputa pelo Rio da Prata, via de acesso essencial ao interior do continente e às suas supostas riquezas minerais (Bandeira, 2010).

Foi na Bacia do Prata, região com 3,1 milhões de $\mathrm{Km}^{2}$, que a história do Brasil e da Argentina, bem como a do Uruguai e Paraguai, "entroncaram-se e entreteceram-se". Os estados nacionais comportam-se conforme tradições e heranças sedimentadas na cultura dos respectivos povos, que eles politicamente organizam e representam. $\mathrm{Na}$ análise de aspectos econômicos e da hegemonia política no enquadramento da região, é importante atentar e não aceitar percepções e versões amplamente difundidas como "tradicional amizade" entre Brasil e EUA ou "secular rivalidade" entre Brasil e Argentina, que se cristalizaram como estereótipos ideológicos $^{22}$ (Bandeira, 2010, p. 38, 41).

Brasil e Argentina, neste período, não competiam economicamente porque suas economias eram complementares. De forma que o foco das tensões não eram as questões comerciais. O Brasil comprava todo o estoque de carne de charque da argentina, por exemplo $^{23}$. O fato do Brasil ser uma monarquia, a única do continente, gerava algumas tensões políticas principalmente no âmbito das fronteiras e dos portos ${ }^{24}$.

Joshua Slocum (1844-1909), comerciante norte-americano, vivenciou a epidemia de cólera na Região do Prata em 1886 e as quarentenas impostas pelo governo brasileiro. A partir de seu relato, podemos ter uma ideia de como esta epidemia e as restrições nos portos afetaram a vida econômica, social e política da região. Em 17 de dezembro de 1886, seu navio parte da costa argentina para o Rio de Janeiro com uma carga de alfafa. Porém, ao invés de atracar no porto do Rio de Janeiro, o cônsul brasileiro ordenou que seu navio fosse para o Lazareto da Ilha Grande para ser desinfectado e descarregado em quarentena (Slocum, 2004, p. 36). Em 18 de dezembro, o Ministro do Império, o Barão de Mamoré, expediu um telegrama que proibia que navios de procedência argentina ou uruguaia atracassem no Brasil. Slocum e sua tripulação tiveram que sair da Ilha Grande e retornar para a Argentina sem conseguir desembarcar a mercadoria (Chaves, 2006, p. 4).

(...) Então, apontando algo que parecia uma pistola, Dom Pedro disse: 'Vaya Homem' (vá embora), 'ou você vai nos passar a cólera'. Tivemos que fazer todo o caminho de volta até Rosário com aquele carregamento de feno -e de problemas (Slocum, 2004, p.37) $[\text { sic }]^{25}$.
Chamar os funcionários do Lazareto da Ilha Grande de "Dom Pedro" é uma ironia não só à forma autoritária e truculenta com que lidaram com a questão, pegando uma pistola, mas também é uma crítica direta ao sistema de governo brasileiro, a monarquia, única existente no continente americano. Slocum, originário de um país republicano, reconhecido pela democracia e o individualismo liberal, teve de lidar com a burocracia pesada e arbitrária do império brasileiro, com seus mandos e desmandos.

Uma outra questão que gerava tensões políticas era a do território das Missões. Em 23 de janeiro de 1890, o Tratado de Montevidéu repartiu o território com uma linha reta que ligava a embocadura dos rios Chopim e Chapecó. Isto afastou a diplomacia brasileira e argentina naquele momento. Mas as rivalidades ou aproximações vão sempre depender do contexto histórico e das relações desses países com as outras potências na luta pelo controle econômico e político da região, em especial EUA e Inglaterra (Bandeira, 2010, p. 58)

Feitas tais considerações, seria oportuno a partir de então inserir nesta análise as discussões relacionadas às controvérsias entre as comunidades médico-científicas, mais precisamente, entre as autoridades sanitárias e seus desacordos em termos de práticas de prevenção às doenças consideradas transmissíveis nos portos - cólera, febre amarela e peste bubônica ${ }^{27}$.

Esta discussão se faz pertinente na medida em que as práticas sanitárias nos portos se davam por meio de um ajuste fino entre medidas preventivas - desinfecções e quarentenas - e a necessidade de livre comércio e circulação de pessoas. A cooperação sanitária internacional consiste na busca por políticas de saúde portuária que fossem uniformes e eficientes, baseadas em princípios científicos e humanitários e capazes de funcionar de forma complementar às atividades do comércio internacional (Cueto, 2007, p.23).

Diferentes percepções entre comunidades científicas e autoridades de saúde pública levaram a ideias e elaborações diversas de políticas sociais no Brasil e na Argentina. Mas além disso, faz-se necessário atentar também para os projetos das elites nacionais para os dois países.

Os anos de 1890, que correspondem ao período de transição entre o ideário da higiene dos miasmas para a microbiologia e a compreensão dos insetos vetores na transmissão de moléstias, são repletos de controvérsias sobre as formas de prevenção da cólera, da febre amarela e da peste bubônica (Benchimol, 1999). 
Estas doenças eram relacionadas ao grande fluxo de mercadorias e pessoas, em especial de trabalhadores imigrantes, pelos portos do Rio de Janeiro, Buenos Aires e Montevidéu. Os acordos que estavam sendo criados tinham como objetivo regulamentar as práticas sanitárias para diminuir os danos causados ao comércio e à circulação de pessoas por conta da prática excessiva de quarentenas. No entanto, questões econômicas, políticas e principalmente, interpretações diversas dos pressupostos científicos que ditavam as práticas de profilaxia atrapalhavam as negociações.

Segundo Caponi (2002a, p.113-116), existiriam dois relatos possíveis para explicar a emergência da medicina tropical e seus usos. No primeiro e mais clássico a medicina tropical teria vindo de uma continuidade e aperfeiçoamento dos programas de investigação e estudos realizados por bacteriologistas e microbiologistas. No segundo relato, a medicina tropical constitui um novo universo de estudo, cujo modelo é representado pelas investigações realizadas em relação à malária, o que gerou a emergência de um novo campo teórico e nova disciplina ${ }^{28}$.

Haveria, então, também dois modelos de inteligibilidade: por um lado a medicina tropical e as enfermidades transmitidas por vetores e, por outro, o modo de compreensão das enfermidades e das estratégias de prevenção defendidas por microbiologistas e higienistas. Os dois modelos explicativos teriam sido adotados no Brasil como estratégias complementares. $\mathrm{Na}$ Argentina, privilegiou-se o programa de investigação iniciado por Pasteur e Koch, a microbiologia. Estas diferenças teriam gerado importantes controvérsias científicas entre estes países cada vez que tentavam estabelecer medidas internacionais de prevenção (Caponi, 2002a, p. 113-116). Além disso, estas diferenças deram origem também a percepções diversas a respeito de políticas sociais entre as duas nações.

Em 1890, a Argentina realizava sua organização urbana, com o controle nos cortiços de enfermidades como a sífilis e a tuberculose. Nos anos seguintes, deu-se a construção de laboratórios e de um instituto de bacteriologia. O objetivo era descobrir novos micróbios, criar vacinas e soros e dar continuidade às medidas clássicas adotadas - desinfecção, saneamento e reorganização urbana- que se viram legitimadas e reforçadas pela microbiologia (Caponi, 2002a, p. 113-116).

Embora a preocupação de antigos e novos higienistas fosse a tuberculose, a sífilis e o alcoolismo, em Buenos Aires, a enfermidade mais temida era a febre amarela, que entrava na categoria de doença tropical. Até 1916, na Argentina, as enfermidades transmitidas por vetores continuaram a ser estudadas com as mesmas estratégias de qualquer outra enfermidade infecciosa, por transmissão direta ou indireta pelos canais clássicos aceitos, como água, o ar e as roupas infectadas. A aliança entre medidas de saneamento e desinfecção propostas por "higienistas clássicos e os avanços dos estudos de microbiologia com suas vacinas e soros parecia bastar para resolver todos os problemas sanitários" (Caponi, 2002a, p. 117).

Ainda que as epidemias que ameaçavam as populações argentina e brasileira fossem as mesmas, as estratégias de investigação e controle eram diferentes. No caso do Brasil, a microbiologia fez a tarefa de converter os efeitos negativos dos trópicos em explicações em termos de bacilos e germes, com estratégias de combate que se opunham à inexorabilidade do determinismo climático. Na Argentina, não se vinculava a situação sanitária com a inexorabilidade geográfica e climática. A capital, Buenos Aires, tem clima temperado, de forma que os temores dos trópicos estariam na sua localização próxima ao Brasil. A proximidade geográfica com o país vizinho - e tropical- facilitaria o contágio. Dessa forma, a "nova higiene"29 na Argentina não precisou romper com os mitos climáticos e legitimou as intervenções dos higienistas clássicos. Desde 1871, a doença mais temida, a febre amarela, foi associada às deficiências de saneamento e a proximidade com o Brasil (Caponi, 2002a, p. 124-125).

As controvérsias no campo da ciência e consequentemente na aplicação das medidas de prevenção adotadas no portos dificultavam a assinatura de acordos de cooperação sanitária. Isto explicaria em parte as diferenças relacionadas às práticas de profilaxia nos portos entre os dois países. Além disso, havia o fato concreto da competição pela atração de imigrantes, peça importante para a constituição do mercado de trabaIho e da própria população (Rebelo \& Caponi, 2012).

Brasil e países do Prata, em especial a Argentina, começaram a disputar imigrantes a partir de 1870. Dentro desta concorrência, é primordial compreender de que forma as condições de saúde e os surtos epidêmicos existentes nas cidades brasileiras e platinas dificultaram a execução das políticas imigratórias para estes países (Chaves, 2006, 2009, p. 39).

Pela lógica econômica, era preciso diminuir os danos sanitários causados ao comércio por causa das medidas de profilaxia nos portos. Por isso a implementação de ações de saneamento nas cidades 
portuárias brasileiras como Santos e Rio de Janeiro. A ênfase na política de imigração, com o subsídio a trabalhadores estrangeiros para a cafeicultura paulista, contribuiu para alavancar o processo das reformas sanitárias e urbanas ${ }^{30}$. Quando os europeus adentravam os portos e se dirigiam para as áreas rurais, eram expostos às doenças transmissíveis e endêmicas nas regiões. Autoridades de saúde pública afirmavam, no entanto, que doenças como a cólera e o tracoma, eram, por sua vez, transmitidas por tais estrangeiros recém-chegados para trabalhar nas lavouras de café. Mas, apesar da possível ameaça que os imigrantes representavam para a saúde pública, seus braços eram essenciais para a economia cafeeira. Dessa forma, a reforma da saúde tornou-se uma preocupação das classes dominantes, tendo a imigração um papel fundamental na promoção de políticas sanitárias (Castro Santos, 2004, p. 261, 262, 266).

Por outro lado, países exportadores de mão de obra para as Américas, como a Itália, procuravam proteger seus patrícios não só das doenças tropicais e das ditas insalubridades das cidades sul americanas, como também da forma de tratamento dispensado a seus cidadãos pelos latifundiários paulistas, acostumados a lidar com escravos e não com trabalhadores assalariados.

\section{A DISPUTA POR MÃO DE OBRA}

Se o Rio de Janeiro era visto como o "túmulo dos estrangeiros" por causa da presença da febre amarela (Cooper, 1975), Buenos Aires tampouco representava um símbolo de salubridade urbana para os países europeus exportadores de mão de obra para a América do Sul ${ }^{31}$.

O jornal O Estado de São Paulo publicou em 6 de agosto de 1911, uma matéria sobre o desenrolar das desavenças diplomáticas entre Itália e Argentina, decorrentes de um surto epidêmico de cólera. Segundo o jornal, a presença da cólera em Buenos Aires colocava em risco os trabalhadores imigrantes italianos e isso preocupava as autoridades italianas ${ }^{32}$.

A disputa por mão de obra na Bacia do Prata foi explicitada durante as discussões para uma terceira convenção sanitária entre Brasil e as repúblicas platinas em 1899. A maior parte dos artigos desta convenção giraram em torno da restrição à movimentação de pessoas entre os portos do Rio de Janeiro e de Buenos Aires, em especial de passageiros de vapores que viajavam nas terceiras classes, em sua maioria imigrantes (Rebelo, 2010a, p. 142).

Havia também uma outra questão que atrapalharia em cheio o comércio brasileiro e a ida da corrente imi- gratória para o país: um dos artigos desta convenção afirmava que a febre amarela era uma doença endêmica no Brasil entre os meses de novembro a maio. Portanto, dentro deste período, os portos brasileiros seriam considerados sempre infeccionados, o que gerava uma série de medidas que restringiam a livre circulação de pessoas e bens. E além disso, causava pânico aos imigrantes de desembarcarem no país e contraírem doenças como a febre amarela, preferindo então os portos de Buenos Aires ou de Montevidéo (Rebelo, 2010a, p. 142).

Este convênio sujeitava os passageiros à inspeção e desinfecção no momento de embarque, nos portos de escala e de desembarque. Quando chegavam ao porto de destino, Buenos Aires, os passageiros de 3 a classe, em sua maioria trabalhadores imigrantes, eram sujeitados a uma nova inspeção e desinfecção e obrigados a permanecer em quarentena. Os navios, depois de inspecionados e desinfectados, ao saírem do Rio de Janeiro em direção ao Prata, só teriam a "livre prática", ou seja, a permissão para atracar e realizar os procedimentos de carga e descarga, assim como o desembarque de pessoas, no fim de cinco dias, mesmo que estivesse em "estado satisfatório", isto é, sem casos de moléstia ${ }^{33}$

As epidemias de cólera e da febre amarela da segunda metade do século XIX ao início do XX causaram na região do Prata muitos prejuízos, tanto comerciais - estremecendo as relações principalmente entre Brasil e Argentina - quanto em nível de desenvolvimento e progresso. A corrente imigratória de trabalhadores europeus, essencial para a economia dos países da região, poderia ser direcionada e redirecionada de diversas formas. A Argentina passara a aplicar longas e vexatórias quarentenas pelas quais passageiros oriundos de portos brasileiros tinham que passar em portos argentinos; cartazes difamatórios eram expostos nos portalos - locais de saída de passageiros dos navios que demandavam os portos brasileiros -com dizeres referentes aos perigos da febre amarela no Rio de Janeiro. A imprensa Argentina também contribuía, publicando propaganda negativa com o intuito de afastar o imigrante do país ao atribuir ao Rio de Janeiro a fama de cidade insalubre e ao Brasil a fama de país inóspito, por causa do seu clima, à civilização europeia ${ }^{34}$. O contrário da Argentina que pelo fato de ter clima temperado estaria salva das doenças tropicais.

Assim, gostaria de levantar mais uma questão que é a mesma apontada por Armus (2007) e diz respeito à compreensão de direitos sociais, relacionados à assistência à saúde nos dois países. Na Argentina, a 
tuberculose foi a doença que recebeu mais atenção no começo do século XX. Foi um tópico relevante em uma agenda que destacava os assuntos da higiene, o ambiente urbano e o assistencialismo no marco mais geral de uma ideologia que se propunha a definir as características determinantes da sociedade argentina. Esta ideologia definirá as bases de um novo estado social, responsável pela proteção e bem-estar da população, com a expansão de certos direitos sociais, solidariedade social, criação de instituições para produzir políticas específicas que permitiriam deixar no passado a filantropia. Reformistas higienistas do final do XIX tentaram confrontar as enfermidades urbanas, em especial as infectocontagiosas e a tuberculose, como enfermidades sociais ${ }^{35}$.

Isso difere significativamente do Brasil, onde a campanha de Oswaldo $\mathrm{Cruz}^{36}$ de combate ao mosquito da febre amarela resolveu por um momento as questões sanitárias do Rio de Janeiro, que deixou de ser cidade insalubre e alavancou a ciência brasileira em nível internacional. A crença na ciência e a reforma urbana no modelo parisiense, teria resolvido por um período todos os problemas. Somente a partir de 1910, o movimento pelo saneamento dos sertões vai apontar as terríveis mazelas sociais com a célebre frase do $d r$. Miguel Pereira: "O Brasil é um grande hospital". Esse Brasil era representado pelo sertões, ou seja, tudo aquilo que existia para além do litoral e do porto do Rio de Janeiro até então esquecido pelas autoridades públicas (Lima \& Hochman, 1996).

Estes dois modelos de compreensão de direito sociais e assistência tem conexões com a forma como as elites nacionais dos dois países pensavam estas questões na construção dos estados e identidades nacionais $^{37}$. Também tem conexões com a ideologia que regia esta compreensão e o uso dela no âmbito de cada sociedade, ou seja, neste caso, com a ideologia liberal da metade do século XIX e suas recepções e influências na América Latina ${ }^{38}$. É necessário pensarmos também na emergência de uma certa ideia de regulação dos riscos sociais no gerenciamento das políticas de saúde pública e de imigração e a relação entre elas.

\section{AUTO-REGULAÇÃO DOS RISCOS E PERCEPÇÕES DO MUNDO LIBERAL}

Se no final do século XIX permanecia a preocupação com a entrada de doenças pestilenciais exóticas (febre amarela, cólera e peste bubônica) pelos portos, no início do século $X X$, demandas sociais com relação à assistência e saúde pública emergiam e apontavam necessidade de mudanças ${ }^{39}$.
No entanto, no âmbito da profilaxia portuária, controvérsias com relação à prevenção de doenças ainda ecoavam no seio da comunidade médico-científica no início do século XX. A descoberta da transmissão da cólera por indivíduos assintomáticos fez com que, em 1910, o Departamento Nacional de Higiene (DNH) argentino impusesse um sistema de análise bacteriológico obrigatório a todos os passageiros imigrantes provenientes de portos infectados (Kepelusz-Poppi, 2011). A cólera grassava em portos italianos de onde saíam os braços imigrantes, disputados em especial por Brasil e Argentina. Esta determinação argentina mudava a marcha da população imigrante, favorecendo neste momento o Brasil.

Nestes dois países, apesar da existência ainda de algumas controvérsias com relação às práticas da microbiologia, o cuidado com a salubridade começou a ser parte das garantias que o estado oferecia à população. Não bastava mais identificar germes, era necessário dar atenção às questões sociais. A saúde se fez, então, como um espaço de consenso político e ideológico na legitimação da intervenção estatal ${ }^{40}$.

O problema não estava mais em demarcar o território, fazer cordões sanitários, fechar portos para o controle da saúde da população. Era necessário a partir de então deixar as circulações acontecerem de forma controlada, de uma maneira que os perigos fossem anulados. Ao invés da quarentena, a vigilância sanitária, ao invés da desinfecção de roupas e objetos, a vacinação nos portos ${ }^{41}$. Deixar a passagem livre para a circulação de mercadorias e pessoas. Os riscos se anulariam por si mesmos ${ }^{42}$

As relações entre estados não são percebidas mais sob a forma de rivalidade, mas sob a forma da concorrência, de conciliação de interesses ${ }^{43}$. Os estados brasileiro e argentino se afirmavam, então, no espaço dos intercâmbio econômicos, da concorrência comercial, da circulação monetária, da concorrência por braços de trabalhadores imigrantes.

Como conciliar interesses? Através da diplomacia e do dispositivo de polícia. A diplomacia vai garantir a manutenção de uma relação de forças, de equilíbrio de forças entre nações. O dispositivo de polícia sustentará o incremento de cada uma dessas forças, sem a ruptura do conjunto. Essa polícia é uma ciência de Estado, é a polícia médica ${ }^{44}$. Trata-se agora de fazer com que o estado não intervenha senão para regular interesses. No ponto de junção dessas duas tecnologias (diplomacia e polícia) deve-se colocar o comércio, a circulação de pessoas e a segurança da população (Foucault, 2005, 2008). 
Assim, percebe-se que a liberdade de comércio era necessária, mas eram necessárias também prevenções que evitassem a hegemonia de um país sobre o outro, além de se garantir a segurança da sociedade. Como equilibrar a balança entre interesses econômicos, políticos, científicos, coletivos, individuais com a questão da segurança da sociedade? Ou como deixar que coisas e pessoas circulassem sem os riscos de epidemias, sem o risco da imigração ilegal, do contrabando e do tráfico de coisas e pessoas? Uma possível resposta seria por meio das técnicas da biopolítica, ou seja, através de um dispositivo de segurança que fornece uma certa resposta aos riscos que as populações correm como doenças, catástrofes, fome, ilegalidades. No centro desta teia, encontramos os indivíduos, os sujeitos de escolhas autônomas, que interagem entre si. Encontramos também a regulação dos espaços da vida, a organização dos territórios, o gerenciamento de uma população estrangeira pelo território ${ }^{45}$. Este seria então o novo modo de governar indivíduos livres (Doron, 2007).

Dessa forma, vê-se emergir a sociedade liberal como possível resposta a estas perguntas, sendo compreendido o liberalismo como a arte de governar sujeitos livres por meio de dispositivos que equilibrariam os riscos de catástrofes, doenças, fome, de forma a garantir a segurança da população. No entanto, precisamos traçar as peculiaridades da construção deste mundo liberal no contexto dos países da Bacia do Rio da Prata, que certamente não é o mesmo das sociedades europeias analisadas por Foucault ${ }^{46}$.

Entre os países da Bacia do Rio da Prata, o otimismo com o crescimento da agroexportação, associado à emergência de ideias liberais, possibilitou discussões entre as elites a respeito da necessidade de promoção de direitos e cuidados, em especial relacionados à saúde e higiene. Possibilitou também a constituição de códigos civis (Abel, 1996. p. 7).

As políticas de saúde tornaram-se elemento de expansão da autoridade estatal pelos territórios. A ideia a respeito da necessidade de coletivização de algum bem-estar levou as elites nacionais a promoverem campanhas para a erradicação de doenças e/ou controle de enfermidades específicas ${ }^{47}$. Isto tornou-se essencial para a ampliação dos mercados de trabalho por meio da corrente imigratória ${ }^{48}$ (Abel, 1996. p. 7).

No caso do Brasil, o processo de independência seguiu rumos diferentes dos outros países da América Latina. Não se pretendia transformar o país em uma república rousseauniana, com base na premissa de que todos os homens são iguais. Não pretendia-se trabalhar a extensão da cidadania, em especial para a população afrodescendente após a abolição (1888) e a proclamação da República (1889). Por outro lado, a ideia de que o governo não deveria violar os direitos econômicos dos cidadãos era bem aceita (Santos, 1998, p.18) ${ }^{49}$.

A proibição do tráfico negreiro, em 1850, levou à escassez de mão de obra e ao recrudescimento das políticas imigratórias. Isto significou um grande passo em direção à criação de um sistema econômico liberal, mas abria um precedente no que se refere à estabilidade do sistema político: os contratos de trabalho dos imigrantes nas fazendas eram assinados dentro de um modelo de semiescravidão ${ }^{50}$. Dessa forma, os latifundiários do café conclamam o governo a expandir sua capacidade regulatória em relação aos contratos econômicos ${ }^{51}$ (Santos, 1978, p.18).

Portanto, temos a inviabilidade do liberalismo político e do sistema de representação onde não havia cidadãos, em um contexto agrário dominado pelas relações de dependência pessoal e pela inexistência de um mercado livre de força de trabalho. O liberalismo político no Brasil nasce sob o estigma da ordem e da autoridade, com o objetivo de fornecer sustentação ao estabelecimento de um estado nacional e não para consagrar a liberdade (Vianna, 1991, p.146).

Ante o exemplo do fracionamento dos países latino-americanos e ante a experiência com as revoltas durante o período regencial (1831-1840) ${ }^{52}$, a solução política encontrada pela elite brasileira foi a adoção de uma monarquia constitucional altamente centralizada. Dessa forma, os excessos republicanos e igualitários permaneceram afastados do corpo social. Mantinha-se, portanto, da agenda liberal a ideia de que o estado não poderia violar os direitos dos cidadãos, aí incluído o direito de ter escravos. O intervencionismo estatal deveria proteger o estoque de mão de obra rural, subsidiando a imigração e atendendo aos interesses agrários. Já a política tarifária protegia os setores urbanos, industriais e os cofres públicos (Gomes, 2002, p. 95).

O modelo de participação política no Brasil da Primeira República, apesar de inegáveis avanços se compararmos com o período imperial - com a abolição do voto censitário, por exemplo - continuava bastante restrito, excluindo analfabetos, mulheres, menores de 21 anos e mendigos (Arruda, 2007, p.179).

No caso específicos dos estrangeiros, por ocasião da primeira eleição republicana brasileira, os imigrantes que entravam no Brasil eram naturalizados compulsoriamente para poderem votar em 1889. Os italianos, 
por exemplo, constituíam $40 \%$ da população nacional. A nacionalização compulsória gerou uma crise entre Brasil e Itália (Rosoli, 1986) ${ }^{53}$. No entanto, observamos nas primeiras décadas do século $X X$, a proibição do alistamento eleitoral de imigrantes como uma forma de mantê-los afastados da vida política e institucional. Esta preocupação vinha da quantidade de estrangeiros que chegavam imersos em ideologias socialistas e anarquistas e que passaram a ser categorizados como "subversivos". Esta percepção deu origem à Lei Adolfo Gordo, de 1907, a lei de expulsão de estrangeiros, imigrantes indesejáveis ${ }^{54}$ (Arruda, 2007, p. 182).

No caso argentino, a adoção do modelo liberal também foi parcial. Uma parte da elite procurava dar legitimidade à sua hegemonia política e ao modelo econômico dominante. $\mathrm{O}$ projeto reformista não se baseava unicamente na extensão dos direitos de cidadania a grupos até então excluídos do sistema político. Não se buscou a completa democratização e nem se evitou recorrer à exclusão e repressão de grupos e indivíduos. O exemplo da campanha anti-colérica, apresentada pelo DNH em 1910, não representa só um esforço de proteção sanitária, mas também de ampla defesa nacional (Kepelusz-Poppi, 2011, p.117).

O que se percebe, portanto, é que os liberais hispano-americanos do século passado viveram e pensaram imersos numa situação singularmente contraditória, ficavam entre as exigências próprias da necessidade de consolidar uma autoridade estatal e aquelas derivadas dos valores do liberalismo político que alentavam (Palermo, 1997, p. 295).

\section{CONSIDERAÇÕES FINAIS}

Neste trabalho, analisou-se as relações entre política e ciência, esta compreendida como campo cultural das ideias ${ }^{55}$, dentro de uma chave interpretativa que procurou atentar para a intersecção entre as políticas de saúde e imigratórias. Inicialmente, ponderei quer as tentativas de construção de práticas sanitárias homogêneas nos portos das nações platinas iam de encontro às controvérsias científicas a respeito da transmissão das doenças consideradas infecciosas na época, mas também, como explorado posteriormente, sofriam influências de tensões políticas e econômicas vinculadas à necessidade de atração de mão de obra imigrante para a conformação dos mercados de trabalho internos.

Mostrou-se como a recusa das nações europeias em discutir as questões pertinentes às doenças tropicais e aos problemas de saúde associados à corrente imigratória fez com que as nações platinas se organizassem dentro de outro modelo de convenção sanitária de acordo com suas demandas.

Além destas questões, vimos também que a partir das primeiras décadas do século $\mathrm{XX}$, as políticas sanitárias entram em processo de transformação, pois não bastava mais só conter epidemias no âmbito dos portos, era necessário começar a expandir direitos sociais em especial relacionados à assistência à saúde. Esta conjuntura é fomentada pelas políticas imigratórias. A recepção de cidadãos oriundos de nações europeias - muitas vezes sob a tutela destes estados nações - gerou a necessidade de se discutir como expandir benefícios sociais de forma mais ampla para a população.

Estas demandas por direitos se configuram dentro do processo de construção dos estados e das identidades nacionais, imersos na recepção da ideologia liberal. O desafio estava em como gerenciar uma massa de cidadãos livres. Pela auto-regulação dos riscos sociais, incluindo as epidemias e a imigração ilegal. Consolidou-se a ideia não de competição entre estados, mas de conciliação de interesses para que a circulação de bens e pessoas ocorresse de forma livre e sem danos à sociedade.

Dentro deste contexto, também foi analisado como as convenções sanitárias influenciaram as relações diplomáticas entre países europeus (exportadores de mão de obra) e platinos (receptores de mão de obra). A partir das convenções, países imigrantistas, como Brasil, Argentina e Uruguai, passaram a ter uma maior autonomia na seleção de trabalhadores imigrantes para constituírem o seus mercados de trabalho.

No caso do Brasil, a recepção de uma população imigrante, branca, assalariada e detentora de certos direitos em seus países de origem, em contraposição à realidade do exército de trabalhadores afro-descendentes, ex-escravos, jogados após 1888 numa sociedade a qual não oferecia espaço algum para a sua inserção no mercado de trabalho, gerou contradições no âmbito do pensamento das elites e suas compreensões do mundo liberal. A coletivização de bem estar não é pensada pela elite como benefício coletivo para o bem de todos, mas como medida de segurança social. Afinal de contas, as doenças promovem uma percepção de interdependência entre classes. Assim observamos, a partir de 1910, a campanha pelo Saneamento dos Sertões, que se traduziu em levar saúde, combate às doenças transmissíveis, para os confins do país até então abandonado pelas autoridades. O que 
não se configura necessariamente como seguridade social, apesar de ser política social de saúde.

No caso da Argentina, percebemos um maior empenho em promover assistência social à população. Esta perspectiva pode ser observada nas campanhas de combate à tuberculose, à sífilis -compreendidas como mazelas sociais- e na política anti-colérica, de 1910, que tinha o imigrante pobre, morador dos cortiços como foco de uma campanha de prevenção e não somente de combate no modelo campanhista como se deu no Brasil.

É necessário atentar ainda para o significado que o conceito de liberalismo tinha para os atores da época e seus usos ${ }^{56}$. No caso dos países da Bacia do Rio da Prata, identificamos outros e novos usos para o termo como: a ideia de liberdade ligada a um ordem institucional; a defesa de garantias, liberdades e direitos

\section{NOTAS}

1. Foucault,1987, p.170-171.

2. Esta relação entre saberes e práticas não acontece de forma direta, linear, sem conflitos, disputas e controvérsias no interior das comunidades cientificas, como mostrou Pierre Bourdieu em O Campo Científico (Ortiz, 2003).

3. A imigração tutelada é aquela amparada desde o início por meio de orientação, ajuda e gerência. Ela é estruturada sobre uma cadeia de relações montada nas pontas das estruturas estatais dos países de emigração e de recepção de mão de obra. Dentro deste processo, cada país possuía interesses específicos. Esse tipo de imigração é o caso da japonesa para o Brasil, a partir de 1908 (Sakurai, 2000, p. 202). Para aprofundar a questão sob o viés das ações orientadas por técnicos do poder tutelar brasileiro, dirigidas para a construção de uma autoridade nacional em matéria de imigração na Primeira República ver Ramos (2006).

4. Hochman, 1993.

5. Ver Porter,1999, p. 48,58; Cueto 2007, p. 28-30

6. As principais práticas de profilaxia sanitária nos portos até então eram as desinfecções e as quarentenas. Estas já vinham sendo criticadas como irracionais e pouco efetivas na contenção de epidemias. Para aprofundar esta questão ver Ackerknecht (1948, p. 564). Sobre o uso da quarentena como mecanismo de protecionismo econômico ver Rebelo (2010b, p. 9).

7. Ver Howard-Jones, 1975; Cueto, 2007; Chaves, 2009.

8. Archivo Histórico de Cancellería, Buenos Aires, Antecedentes para la convención de Rio de Janeiro suministrados al individuais, como nos decretos sobre liberdade de imprensa e seguridade individual; a institucionalização do poder em um regime republicano e representativo e a necessidade também de limitar tal poder para assim garantir certas liberdades (Wasserman, 2012 p.55).

Assim, este artigo teve o objetivo de construir um nexo entre imigração, ciência e políticas de saúde. A imigração é compreendida como o motor que gerou inflexões na assinatura de convênios sanitários a partir dos quais se regulamentou os espaços de circulação de pessoas e mercadorias no final do século XIX e início do XX. Era necessário neste momento prevenir, garantindo, ainda assim, o livre fluxo. Ao invés da quarentena de todos, a observação somente dos doentes; ao invés das desinfecções, vacinas. Uma certa economia dos riscos, que agora deveriam se anular por si mesmos em uma espécie de auto-regulação.

Ministro del Interior, Dr. Joaquin V. Gonzalez - Buenos Aires, Abril 8 de 1904.

9. Neste artigo, optou-se por manter as fontes em sua escrita original e sem a tradução para o português.

10. Isto ocorre também no que diz respeito aos Congressos Médicos Latino Americanos. Almeida (2006) destaca a dinâmica local de redes medico-científicas por meio da análise de tais congressos e das Exposições Internacionais de Higiene das primeiras décadas do século XX. A internacionalização da ciência no continente muitas vezes é vista sob uma ótica centrada na relação entre os países latino-americanos com países europeus, numa perspectiva mais transatlântica e menos intercontinental. No entanto, a autora mostra a existência de uma comunidade medico-científica regional muito atuante no continente. E como resultado desta interpretação, vislumbra-se uma circularidade de ideias e de pessoas, transpondo as fronteiras físicas e imaginárias da América Latina. Este processo levou tal comunidade local a pensar soluções diversas para as questões médicas e sanitárias.

11. Archivo Histórico de Cancellería, Buenos Aires, Antecedentes para la convención de Rio de Janeiro suministrados al Ministro del Interior, Dr. Joaquin V. Gonzalez - Buenos Aires, Abril 8 de 1904

12. As primeiras convenções platinas foram assinadas em $1873,1887,1899,1904$. Sobre as duas primeiras ver Chaves $(2009,2008)$, sobre as duas últimas ver Rebelo (2010b, 2013).

13. Sobre o período de transição entre os pressupostos da higiene dos miasmas e os da microbiologia ver Benchimol (1999) e Caponi (2002b). 
14. Archivo Histórico de Cancellería, Buenos Aires, Antecedentes para la convención de Rio de Janeiro suministrados al Ministro de Relaciones Exteriores, Sr. José A. Terry, Buenos Aires, Julio 5 de 1904.

15. Archivo Histórico de Cancellería, Buenos Aires, Antecedentes para la convención de Rio de Janeiro suministrados al Ministro de Relaciones Exteriores, Sr. José A. Terry, Buenos Aires, Julio 5 de 1904, p.106.

16. Archivo Histórico de Cancellería, Buenos Aires, Antecedentes para la convención de Rio de Janeiro suministrados al Ministro de Relaciones Exteriores, Sr. José A. Terry, Buenos Aires, Julio 5 de 1904, p.104.

17. Esta pergunta é a mesma feita por Peter Baldwin (1999), referindo-se ao caso França e Inglaterra. Aqui, repete-se para analisar a situação entre Brasil, Argentina e Uruguai.

18. Baldwin (1999) faz uma crítica à visão de Ackerknecht (1948), a qual o autor se refere como maniqueísta: a dicotomia profilática entre "conservadores quarentenário" e "liberalismo sanitário", na questão da etiologia da cólera no séc XIX, entre contagionistas e localistas respectivamente. Para aprofundar este debate entre política e ciência, em especial a crítica que Baldwin faz à perspectiva de Ackerknecht ver Rebelo (2013, p.772-775).

19. Seguindo Roger Chartier (2012), caracterizo aqui o campo científico dentro da categoria de campo cultural das ideias.

20. Esta questão foi objeto de controvérsias científicas até a assinatura da convenção de 1904, quando a teoria defendida pelo médico Carlos Finlay, em 1892, de que a febre amarela era transmitida pelos culicídios, foi oficialmente aceita (Benchimol \& Silva, 2008).

21. Sobre a influência dos EUA e da Inglaterra na região ver Bandeira (2010).

22. Ver também Castro (2012).

23. Ver Chaves, 2006

24. Bandeira, 2010, p.38, 41; Castro (2012).

25. Repelir à bala navios com epidemias a bordo ou doentes em fronteiras, portos e estações não era prerrogativa só da monarquia brasileira. A prática da quarentena à bala nos EUA foi assunto de um conhecido periódico médico brasileiro em 1895, quando publicou uma matéria cujo o titulo era "Quarentena Selvagem" e dizia o seguinte: "No Arkansas (Estados Unidos do Norte) um pobre varioloso por se ter evadido de uma estação quarentenária, onde ficara retido, foi morto a tiro por um empregado da quarentena" (O Brazil-Médico, 1895, p. 383). Neste mesmo periódico, foi publicada uma outra matéria em 1899 sobre o descumprimento da Convenção de 1887 pela Argentina que passara a obrigar os navios procedentes do porto Rio de Janeiro a purgarem longas quarentenas, "repelindo à bala um navio porque tinha a bordo doente de febre amarela" (O Brazil-Médico, ano XIII, n. 45, 1 de dezembro de 1899).

26. Ver também Castro (2012).

27. Nos relatórios, regulamentos e convenções a categoria "moléstias pestilenciais exóticas" refere-se à febre amarela, cólera e peste bubônica. Para estas, havia regulamentação para a profilaxia específica nos portos, acordada nas convenções.

28. Para Edler (1999, p. 204), a descoberta de Patrick Manson reformulava uma série de questões no campo da patologia, cujas respostas pressupunham o domínio de novas áreas do saber - Parasitologia, Biogeografia, Entomologia, Helmintologia. Estas diferentes dinâmicas de pesquisa se somariam a outras tradições emergentes como a Protozoologia, Bacteriologia, para comporem, na última década do século XIX, o repertório de disciplinas conexas à Medicina Tropical.

29. O termo nova higiene é utilizado aqui não como uma quebra de paradigma, como se existisse uma velha higiene e nem como um novo conceito. É uma forma conveniente de apontar certas diferenças na legislação e nas práticas sanitárias entre dois períodos. O termo aparece também nos relatórios, regulamentos e convenções.

30. Sobre as reformas urbanas no Rio de Janeiro ver Benchimol, 2003.

31. É importante ressaltar que a febre amarela no Rio de Janeiro era concreta e real. Na epidemia de 1850, um terço da população da cidade foi dizimada pela doença. Durante os anos entre 1852 e 1895, mais de 15 mil pessoas morreram, 4 mil delas durante as epidemias de 1891, 1892 e 1894 . A epidemia deste último ano foi a pior de todos os tempos (Cooper, 1975, p. 679).

32. O Estado de São Paulo, 6 de agosto de 1911

33. O Brazil-Médico, ano XIII, n.45, 1 de dezembro de 1899, pp. 437, 438.

34. Relatório do Ministério da Justiça e Negócios Interiores - RMJNI, Relatório do Diretor Geral de Saúde Pública, 1904/1905: A-A-15; O Brazil-Médico, 1905, ano XIX, vol 1, pp. 227.

35. Precisamos levar em conta também que o funcionamento da higiene e da medicina a partir do século XVIII se constituiu como instâncias de controle social, em especial direcionado à população pobre. As medidas de saúde pública, historicamente, implicaram uma série de intervenções autoritárias como mostrou Foucault (1979). No entanto, é preciso ressaltar que tais medidas autoritárias nunca foram recebidas sem resistências, inclusive deram origem a revoltas sociais como no caso da Revolta da Vacina, em 1904, no Rio de Janeiro. 
36. Sobre Oswaldo Cruz e o campanhismo ver Brito, 1995, p.13.

37. Ver Hochman, Palmer \& Di Liscia (2012).

38. Ver Sebastián (2012).

39. Ver Weindling (1995).

40. Sobre esta questão ver Hochman, 1998.

41. Sobre as mudanças na aplicação das práticas de profilaxia nos portos no final do século XIX às primeiras décadas do século XX ver Rebelo (2013).

42. Doron, 2007.

43. Ver Foucault, 2008.

44. Sobre a polícia médica ver Rosen (1978).

45. Ramos (2006).

46. Especialmente nos textos da última fase do autor, Em Defesa da Sociedade (2005) e Segurança, Território, População (2008). Sobre a recepção no mundo intelectual brasileiro do liberalismo, positivismo e evolucionismo, na perspectiva local ver Carvalho (2012, p.392-393) e Coser (2010).

47. Hochman (1998)

48. Para Fairchild (2004, p. 528-530), a despeito da exclusão, a história do exame médico nos portos é a da inclusão. 0 objetivo do Public Health Service não estava em mandar os trabalhadores imigrantes de volta para a Europa, mas em introduzi-los nos valores da sociedade industrial norte-americana para a formação do mercado de trabalho interno. De forma que era necessário não restringir, mas controlar e prevenir a entrada daqueles que não poderiam trabalhar e se sustentar, o que os levariam à dependência do Estado, "Likely do become a public charge".

49. Neste artigo, discuti-se política social e inclusão no início do século XX no Brasil, tendo como chave de interpretação o processo de coletivização da saúde. As políticas sociais são analisadas dentro do processo histórico de generalização da interdependência humana e das respostas aos problemas por ela gerados, resultantes do surgimento dos Estados Nacionais e do desenvolvimento do capitalismo. Seguimos os argumentos de Hochman (1993, p.1-3), que por sua vez segue De Swaan (1990) e Elias (1989). Os elos de interdependência que fundariam a necessidade de "coletivização" do bem-estar para des- tituídos são os efeitos externos, as consequências indiretas de tais adversidades para aqueles que são atingidos, apesar de não compartilharem de tais problemas. Dessa forma, dialoga-se também com a perspectiva de Foucualt em sua última fase $(2005,2008)$. Não pretende-se uma avaliação dos resultados de tais políticas, mas mostrar que houve, efetivamente, ao longo do período, constituição de poder público por meio do sanitarismo, com impactos no sistema politico, em especial sobre os grupos envolvidos, como imigrantes, e sobre a capacidade do Estado de criar e gerenciar políticas.

50. Por causa das péssimas condições de trabalho de imigrantes italianos nas fazendas paulistas, a Itália, em 1902, sob o decreto Prinetti, proibiu durante um período a imigração subsidiada para o Brasil. No começo do século XX, a Itália, o maior país exportador de mão-de-obra para a América, dera início a uma política imigratória que tentava combinar tutela nacional, preocupação demográfica, proteção social e benefícios para emigrantes. O Estado italiano passa a elaborar dispositivos de ação pública para proteger a sua população imigrante, em especial durante a travessia marítima, gerando "preocupações humanitárias sob a lógica dos lucro das companhias marítimas" e também no plano internacional de negociações com os países receptores no sentido de melhorar as condições de recepção e proteção de seus trabalhadores (Douki, 2011, p. 375-379).

51. As ideias liberais na elite brasileira são difusas. Existiam também aqueles que não defendiam qualquer tipo de intervenção estatal, pregavam a descentralização e a imigração livre como era o caso de Tavarez Bastos (Santos, 1978, p.38). Sobre as ideias liberais e as polêmicas entre Oliveira Viana e Tavares Bastos ver Vianna (1991).

52. Ver Morel (2003)

53. A grande naturalização decretava que o estrangeiro residente no Brasil em 15 de novembro de 1889 automaticamente recebia naturalidade brasileira, a menos que se reportasse de modo contrário às autoridades competentes. O decreto assegurava a permissão de alistamento eleitoral para os naturalizados alfabetizados que não conheciam a língua portuguesa (Seyferth, 2011).

54. Sobre imigrantes indesejáveis ver Menezes (1996). Sobre a diplomacia brasileira antirrevolucionária ver García, 2004.

55. Chartier (2012).

56. Sobre este assunto ver também Bell (2014). 


\section{BIBLIOGRAFÍA}

Abel, Christopher (1996), "Health, Hygiene and Sanitation in Latin America, c.1870 to c. 1950", University of London, ISA Research Papers (42), p. 9, [en línea], disponible en: http:// sas-space.sas.ac.uk/3408/, [consultado el 29/07/2016].

Ackerknecht, Erwin H (1948), "Anticontagionism Between 1821 and 1867", Bulletin of History of Medicine, 22, pp. 562-593, p. 564, [en línea], doi: 10.1093/ije/dyn254

Albuquerque, Marli Brito Moreira de (1989), "Modernização do espaço portuário do Rio de Janeiro e a organização sindical: os pigmeus no boulevard", Estudos, 12, pp. 31-33.

Almeida, Marta (2006), "Circuito aberto: idéias e intercâmbios médico-científicos na América Latina nos primórdios do século XX", História, Ciências, Saúde - Manguinhos, 13 (3), pp. 733-57

Armus, Diego (2007), La ciudad impura. Salud, tuberculosis y cultura en Buenos Aires (1870-1950), Buenos Aires, Edhasa.

Arruda, Pedro Fassoni (2007), "Liberalismo, direito e dominação da burguesia agrária na Primeira República brasileira (1889-1930)", Ponto-e-Vírgula. Revista de Ciências Sociais, 1, pp. 162-168, p.179, 182

Baldwin, Paul (1999), Contagion and the State in Europe 18301930, New York, Cambridge University Press.

Bell, Duncan (2014), “What Is Liberalism?”, Political Theory, 42 (6), pp. 682-715, [en línea], doi: 10.1177/0090591714535103

Bandeira, Luiz Alberto Moniz (2010), Brasil, Argentina e Estados Unidos: conflito e integração na América do Sul (da Tríplice Aliança ao Mercosul), 1870-2003, Rio de Janeiro, Civilização Brasileira, p.38, 41, 58

Benchimol, Jaime Larrry (1999), Dos micróbios aos mosquitos: febre amarela e a revolução pasteuriana no Brasil, Rio de Janeiro, Fiocruz.

Benchimol, Jaime Larry (2003), "Reforma urbana e Revolta da Vacina na cidade do Rio de Janeiro". En: Ferreira, Jorge y Delgado, Lucília de Almeida Neves (eds.), O Tempo do Liberalismo Excludente: da Proclamação da República à Revolução de 1930, Rio de Janeiro, Civilização Brasileira (O Brasil Republicano, v. 1), pp. 231-286.

Benchimol, Jaime Larry y Silva, André Felipe Cândido da (2008), "Ferrovias, doenças e medicina tropical no Brasil da Primeira República", História, Ciências, Saúde - Manguinhos, 15 (3), pp. 719-762.

Brito, Nara (1995), Oswaldo Cruz: a construção de um mito na ciência brasileira, Rio de Janeiro, Editora Fiocruz.

Bynum, William F. (1993), "Policing Hearts of Darkness: aspects of the international sanitary conference", History and philosophy of the life sciences, 15, pp. 421-434.
Caponi, Sandra (2002a), "Trópicos, micróbios y vetores", História, Ciências, Saúde-Manguinhos, Rio de Janeiro, v.9, Suplemento "Ciência, saúde e poder", pp. 111-138.

Caponi, Sandra (2002b), "Entre miasmas y microbios: la vivienda popular higienizada", Cadernos de Saúde Pública, Rio de Janeiro, 18 (6), pp. 1665-1674.

Carvalho, José Murilo de (2012), “O papel e a complexidade do liberalismo no Brasil”, Estudos Avançados, 26 (76), pp. 391-394.

Castro, Fernando Vale (2012), Pensando um continente: a Revista Americana e a criação de um projeto cultural para a América do Sul, Rio de Janeiro, Mauad Editora Ltda: FAPERJ.

Castro Santos, Luiz Antônio de (1985), “O pensamento sanitarista na Primeira República: uma ideologia de construção da nacionalidade". Dados, Revista de Ciências Sociais, Rio de Janeiro, 28, pp. 193-210.

Castro Santos, Luiz Antonio de (2004), "Poder, ideologia e saúde no Brasil da Primeira Repúbica: ensaio de sociologia histórica". En: Armus, Diego \& Hochman, Gilberto (eds.), Cuidar, Controlar, Curar: ensaios históricos sobre a saúde e doença na América Latina e Caribe. Rio de Janeiro, Ed. Fiocruz, pp. 249-293.

Chartier, Roger (2012), Autoria e história cultural da ciência, Rio de Janeiro, Beco do Azougue.

Chaves, Cleide de Lima (2006), “A ciência médica na Convenção Sanitária firmada entre o Brasil, a Argentina e o Uruguai em 1887", Anais Eletrônicos do VII Encontro Internacional da ANPHLAC, [en línea], disponible en: http://anphlac.fflch. usp.br/sites/anphlac.fflch.usp.br/files/cleide_de_lima_ chaves.pdf, [consultado el 31/07/2-16.

Chaves, Cleide de Lima (2008), "Pesquisadores de uma verdade experimental ainda não comprovada: a ciência médica na convenção sanitária entre Brasil, Uruguai e Argentina." Revista Brasileira de História da Ciência, 1 (2), pp. 122-136.

Chaves, Cleide de Lima (2009), As Convenções Sanitárias Internacionais entre o Império Brasileiro e as Repúblicas Platinas (1873 e 1887), Tese de Doutorado. Programa de Pós- Graduação em História Social, Instituto de Filosofia e Ciências Sociais, da Universidade Federal do Rio de Janeiro.

Cooper, Donald B. (1975), “Brazil's long fight against epidemic disease, 1849-1917, with special emphasis on yellow fever". Bulletin of the New York Academy of Medicine, 51 (5), pp. 672-696.

Coser, Ivo (2010), “O pensamento político dos liberais: o conceito de americanismo na construção do estado brasileiro". Perspectivas: Revista de Ciências Sociais, 38, pp. 49-73.

Cueto, Marcos (2007), o Valor da Saúde: História da Organização Pan-Americana da Saúde, Rio de Janeiro, Editora Fiocruz. 
De Swaan, Abraam (1990), In care of the State, London, Polity Press.

Doron, Claude-Olivier (2007), "Biopolitique et Prévention des Risques". Coloque Politique de Santé, Prévention, Normes et Disciplines des Corps, Musée de Beaux-Arts, Caen, 08/10/2008.

Douki, Caroline (2011), "Protection sociale et mobilité transatlantique: les migrants italiens au début du XXe siècle." Annales. Histoire, sciences sociales, 66 (2), pp.375-410.

Edler, Flávio Coelho (1999), A constituição da medicina tropical no Brasil oitocentista: da climatologia à parasitologia médi$c a$, Tese de doutorado, IMS/UERJ. Rio de Janeiro.

Elias, Norbert (1989), O que é sociologia?, Lisboa, Edições 70.

Fairchild, Amy L. (2003), Science at the borders: immigrant medical inspection and the shaping of the modern industrial labor force, Baltimore, Maryland, The Johns Hopkins University Press.

Fausto, Boris y Devoto, Fernando (2004), Brasil e Argentina: um ensaio de história comparada (1850-2002), São Paulo, Editora 34 .

Foucault, Michel (1979), Microfísica do poder, Rio de Janeiro, Edições Graal.

Foucault, Michel (1987), Vigiar e punir: o nascimento da prisão, Petrópolis, Vozes.

Foucault, Michel (2005), Em defesa da sociedade: curso no Collège de France (1975-1976), São Paulo, Martins Fontes.

Foucault, Michel (2008), Segurança, território, população, Curso dado no Collège de France (1977-1978), São Paulo: Martins Fontes.

Garcia, Eugenio V. (2004), "Antirevolutionary diplomacy in oligarchic Brazil, 1919-30", Journal of Latin American Studies, 36 (4), pp. 771-796.

Gomes, Angela de Castro (2002), “A República não-oligárquica e o liberalismo dos empresários". História econômica da Primeira República, São Paulo, EDUSP/Imprensa Oficial.

Hochman, Gilberto (1993), "Regulando os efeitos da interdependência: sobre as relações entre saúde pública e construção do Estado (Brasil 1910-1930)", Estudos Históricos, 6, pp. 40-61.

Hochman, Gilberto (1998), A era do saneamento: as bases da política de saúde pública no Brasil, São Paulo, Hucitec/ Anpocs.

Hochman, Gilberto; Steven Palmer y Maria Silvia Di Liscia (2012), Patologías de la Patria: enfermedades, enfermos y nación en América Latina, Buenos Aires, Lugar Editorial.
Howard-Jones, Norman (1975), The Scientific Background of International Sanitary Conferencer, 1851-1938, Genebra, World Health Organization.

Kepelusz-Poppi, Ana María (2011), “José Penna y Salvador Mazza en tiempos del cólera. Salud, inmigración y legitimidad política en la Argentina de 1910", Temas de Historia Argentina y Americana 19, p.117, [en línea], disponible en: http://bibliotecadigital.uca.edu.ar/repositorio/revistas/ jose-penna-salvador-mazza-tiempos.pdf, [consultado el 31/07/2016].

Lima, Nísia Trindade y Hochman, Gilberto (1996), "Condenado pela raça, absolvido pela medicina: o Brasil descoberto pelo movimento sanitarista da primeira república". En: Maio, Marcos Chor y Santos, Ricardo Ventura (eds.). Raça, ciência e sociedade, Rio de Janeiro, Editora Fiocruz/Centro Cultural Banco do Brasil.

Lima, Nisia Trindade (2002), "O Brasil e a Organização Pan-Americana da Saúde: uma história em três dimensões". En: Finkelman, Jacob (org.), Caminhos da saúde pública no Brasil, Rio de Janeiro, Editora Fiocruz, pp. 24-116.

Löwy, llana (2006), Vírus, Mosquitos e Modernidade. A febre amarela no Brasil entre ciência e política, Rio de Janeiro, Fiocruz.

Menezes, Lená Medeiros de (1996), Os indesejáveis: desclassificados da modernidade. Protesto, crime e expulsão na Capital Federal (1890-1930), Rio de Janeiro, EDUERJ.

Morel, Marco (2003), O período das Regências (1831-1840), Rio de Janeiro, Zahar.

Ortiz, Renato (2003), A sociologia de Pierre Bourdieu, São Paulo, Olho d'água.

Palermo, Vicente (1997), “Pensamento político progressista no liberalismo argentino e mexicano do século XIX: Juan Bautista Alberdi e Justo Sierra", Revista Estudos Históricos, 10 (20), pp. 295-320.

Porter, Dorothy (1999), Health, Civilization and the State: a History of Public Health from Ancient to Modern Times, London and New York, Routledge.

Ramos, Jair de Souza (2006), O poder de domar do fraco: construção de autoridade e poder tutelar na política de povoamento do solo nacional, Niterói, Eduff.

Rebelo, Fernanda (2010a), A Travessia: imigração, Saúde e profilaxia internacional (1890-1926), Tese de doutorado. Programa de Pós-Graduação em História das Ciências e da Saúde da COC/Fiocruz.

Rebelo, Fernanda (2010b), “Controvérsias científicas no Prata e o problema imigratório entre Brasil e Argentina no final do século XIX". En: Anais Eletronicos do 12 Seminário Nacional de História da Ciência e da Tecnologia e 7o Congresso 
Latino-americano de História da Ciência e da Tecnologia, Salvador, Bahia, 12 e 15 de novembro.

Rebelo, Fernanda y Caponi, Sandra (2012), “Controvérsias Científicas no Prata: imigração, profilaxia e cooperação sanitária no final do século XIX e início do XX". En: Anais Eletronicos do 13으 Seminário Nacional de História da Ciência e da Tecnologia e 8o Congresso Latino-americano de História da Ciência e da Tecnologia, pp. 1005-1017, [en línea], disponible en: http://www.sbhc.org.br/site/anais2012.

Rebelo, Fernanda (2013), "Entre o Carlo R. e o Orleannais: a saúde pública e a profilaxia marítima no relato de dois casos de navios de imigrantes no porto do Rio de Janeiro, 1893-1907", História, Ciências, Saúde - Manguinhos, Rio de Janeiro, 20 (3), jul.-set., pp.765-796.

Rosen, George (1978), Da polícia médica à medicina social, Rio de Janeiro, Graal.

Rosoli, Gianfausto (1986), "La crise des relations entre l'Italie et le Brésil: la grande naturalisation (1889-1896)", Revue européenne de migrations internationales. 2 (2), Novembre, Amériques, pp. 69-90.

Sakurai, Célia (2000), “Imigração Japonesa no Brasil: Um exemplo de Imigração Tutelada (1908-1941)”. En: Fausto, Boris (Org.) Fazer a América, São Paulo, Edusp, pp. 201-238.
Santos, Wanderley Guilherme dos (1998), "A práxis liberal no Brasil: propostas para reflexão e pesquisa". En: Santos Wanderley Guilherme dos, Décadas de espanto e uma apologia do democrático, Rio de Janeiro, Rocco, pp. 9-61.

Sebastián, Javier Fernández (2012), La aurora de la libertad: los primeros liberalismos en el mundo ibero-americano, Madrid, Marcial Pons Historia.

Seyferth, Giralda (2011), "A dimensão cultural da imigração". Revista Brasileira de Ciências Cociais, 26 (77), pp. 47-62.

Slocum, Joshua (2004), A viagem do Liberdade, São Paulo, Planeta do Brasil.

Vianna, Luiz Werneck (1991), "Americanistas e iberistas: a polêmica de Oliveira Vianna com Tavares Bastos", Dados, Revista de Ciências Sociais, 39 (3), pp. 145-190.

Wasserman, Fabio (2012), "Entre la Moral y la política. Las transformaciones conceptuales de 'liberal' en el Río de la Plata (1780-1850)". En: Sebastián, Javier Fernández, La aurora de la libertad: los primeros liberalismos en el mundo ibero-americano, Madrid, Marcial Pons Historia, pp. 37-73.

Weindling, Paul (1995), International health organisations and movements, 1918-1939, New York, Cambridge University Press. 